祖父江友孝 1

要旨——わが国では, 1987 年に X 線と喀痰細胞診による肺がん検診が老人保健事業に導入されて, すでに 18 年が経 過している. 事後的にではあるが, 宮城・新潟・岡山などの地域で行われた症例対照研究により, 肺がん死亡減少効果 を示唆する成績を得ており, 有効性を示す科学的証拠が得られている. 従って, 肺がん検診が正しく実施されていれば, その成果が目に見える形で確認されるはずである。ところが, 年齢調整罹患率 (地域がん登録研究班全国推計值) と年 齢調整死亡率(人口動態統計全国值)の年次推移を対数表示してみると, 両者はほとんど平行に推移している。これは, 早期発見による死亡減少効果が全国レベルではほとんど観察されないことを示している. 一方で, 宮城・新潟・岡山の 女性においては, 全国に比べて肺がん死亡率の減少の程度が大きい.これらの地域では, 精度の高い肺がん検診が高い 受診率で実施されているのかもしれない. その他の地域においては, 現状の肺がん検診を漫然と継続しても肺がん死亡 減少は期待できず，根本的な見直しが必要である。（肺癌. 2006;46:859-862）

索引用語——肺がん, 集団検診, 胸部 X 線, 有効性, 死亡率

\title{
Mass Screening by Indirect Method
}

\author{
Tomotaka Sobue ${ }^{1}$
}

ABSTRACT — In Japan, lung cancer screening using chest X-ray and sputum cytology has been conducted for 18 years since 1987. Although it is retrospective, the efficacy of lung cancer screening in terms of lung cancer mortality reduction has been evaluated by several case-control studies, such as those conducted in Miyagi, Niigata and Okayama Prefectures, and positive results have been reported. Therefore, if it is implemented properly, its effect should be observed in national statistics. However, age-adjusted incidence and mortality for lung cancer have been showing almost parallel trends so far, which means effectiveness of lung cancer screening has not been observed at the national level. On the other hand, in Miyagi, Niigata and Okayama Prefectures the magnitude of decrease in lung cancer mortality seemed to be greater than the national average, which suggested high-quality screening had been conducted with higher participation rate in these areas. In other areas, no apparent effects can be expected by continuing current activities, and fundamental discussion of the problem is needed. (JJLC. 2006;46:859-862)

KEY WORDS — Lung cancer, Screening, Chest X-ray, Efficacy, Mortality

\section{1. 胸部 X 線を用いた肺がん検診の有効性}

胸部 X 線を用いた肺がん検診の死亡率減少効果の評 価研究としては, わが国ではこれまでに 6 つの症例対照
研究が行われている. ${ }^{1-6}$ そのうちの 4 つで統計学的有意 性をもって死亡減少効果が示され, 残りの 2 つでも死亡 減少効果を示唆する成績であった. 症例対照研究は, Selfselection Bias の影響を受けるため, 結果の解釈には慎重

Reprints: Tomotaka Sobue, Statistics and Cancer Control Division Research Center for Cancer Prevention and Screening, National Cancer Center, 5-1-1 Tsukiji, Chuo-ku, Tokyo 104-0045, Japan (e-mail: tsobue@ncc.go.jp).

(C) 2006 The Japan Lung Cancer Society
1国立がんセンターがん予防・検診研究センター情報研究部。 別刷請求先 : 祖父江友孝, 国立がんセンターがん予防・検診研究 センター情報研究部， =104-0045 東京都中央区築地 5-1-1 (e-mail: tsobue@ncc.go.jp).

1Statistics and Cancer Control Division Research Center for Cancer Prevention and Screening, National Cancer Center, Japan. 


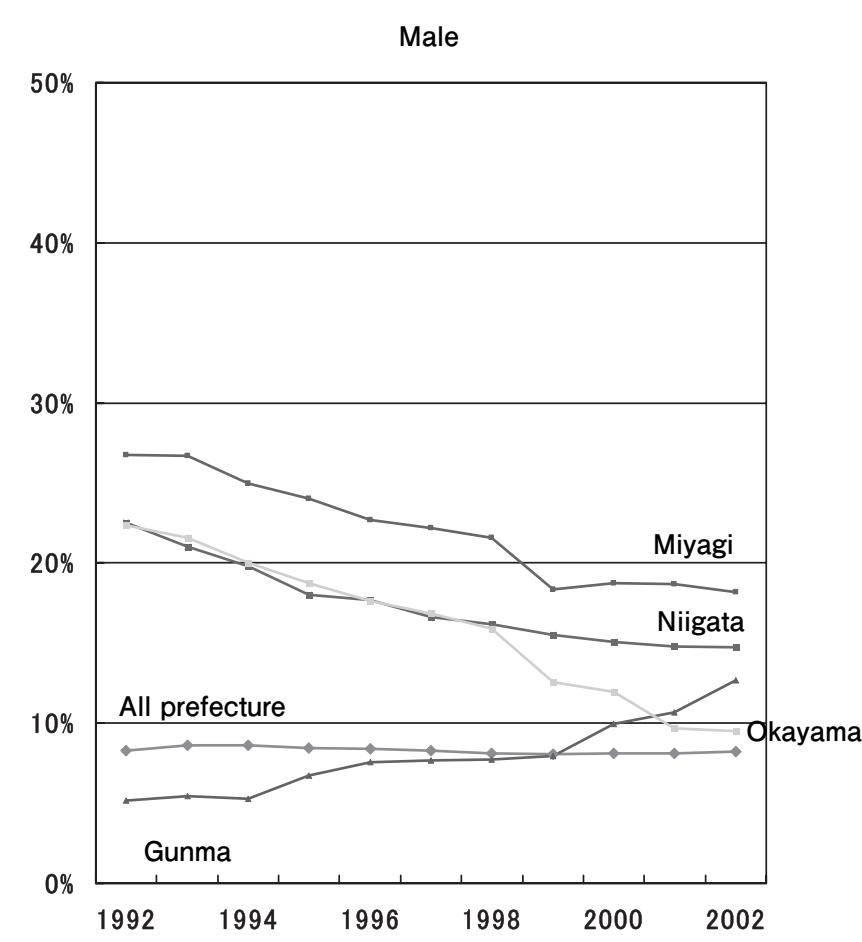

Figure 1. Trends of coverage rate (50-60 y.o.).

を要するが,「新たながん検診手法の有効性評価」報告書 (2001 年 3 月, 主任研究者 久道茂)では, この結果を受 けて,「わが国の胸部 X 線と喀痰細胞診 (高危険群のみ) を組み合わせた肺がん検診は, 死亡率減少効果があると する相応の根拠がある」と評価している.7

一方，欧米では，胸部 X 線による肺がん検診は，Randomized Controlled Trial（RCT）に扔いて死亡率減少効 果が確認されなかったことから，諸外国では一般住民に 対しては推奨されていない. US Preventive Services Task Force（USPSTF）では, 1996 年版の評価で,「D」 （当該サービスを日常的に無症状の患者に対して提供す ることに反対する。すすなわち，当該サービスに効果がな い，あるいは，不利益が利益を上回るとする少なくとも 相応の証拠があると判断する) との評価をしていた. 8 と ころが，2004 年 5 月に改訂されたUSPSTF の肺がん検 診に対する評価判定は「I」(当該サービスを日常的に提供 することについて，勧めるまたは反対する勧告を出すた めの証拠が不十分であると結論する.すなわち, 当該サー ビスに効果があるとする証拠がないか，質が悪いか，あ るいは, 一致した結果が得られていないため, 利益と不 利益のバランスを判断できない) と変更された. ${ }^{9} こ の$ 変 更には，わが国の症例対照研究の成績が大きく影響して いると考えられるが，これらの対象地域は，熱心な検診 指導者により精度の高い検診が継続的に行われた地域で あり，これと同レベルの精度管理が行われない限り有効
Female

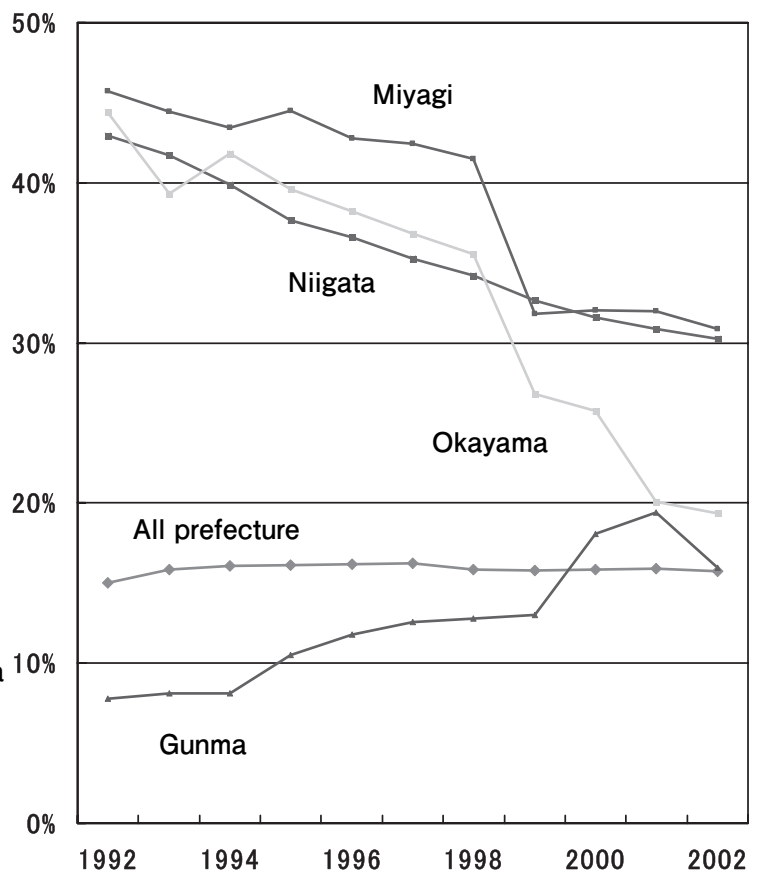

性が保たれないことには留保する必要がある。

\section{2. 老人保健事業による肺がん検診の死亡率減少効果}

評価研究の成績として死亡減少効果を示すと解釈され た後も, それが現実の施策として展開された結果として, 対象者における死亡減少効果をもたらしたかどうかを確 認する必要がある．米国における乳がん死亡率と罹患率 には, 1990 代後半以降乘離減少が認められ, その乘離の 半分はマンモグラフィを用いた乳がん検診による寄与と 推定されている.10 わが国では, 胸部 X 線による肺がん 検診が 1987 年に老人保健事業として導入されてからす でに 18 年が経過している．1975～97 年の年歯令調整䍜患 率 (地域がん登録研究班全国推計值) 11 と年齿調整死亡率 (厚生労働省人口動態統計全国值)の年次推移を対数表示 してみると, 肺がんの場合, 男女ともすべての年齢層で, 両者はほとんど平行に推移している。 これは, これまで のところ早期発見による死亡減少効果が全国レベルでは ほとんど観察されないことを示している，すなわち，理 想的な状況における死亡率減少効果は確認されている が，現実の施策レベルではそれが達成されていない。こ れは,わが国の多くの地域において受診率が低いこと, 精度管理が徹底されていないことが原因と考えられる.

\section{3. 受診率の高い地域における肺がん死亡率の推移}

老人保健事業報告によると, 肺がん検診の受診率には, 
(per 100,000)

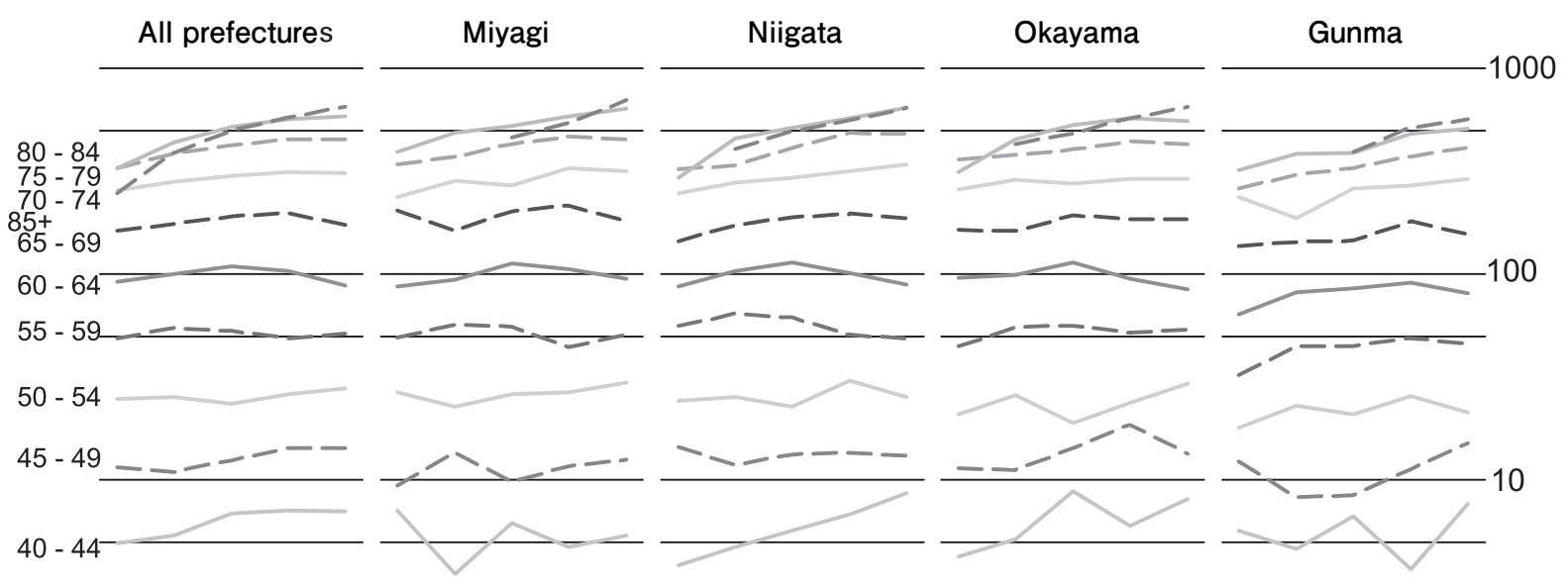

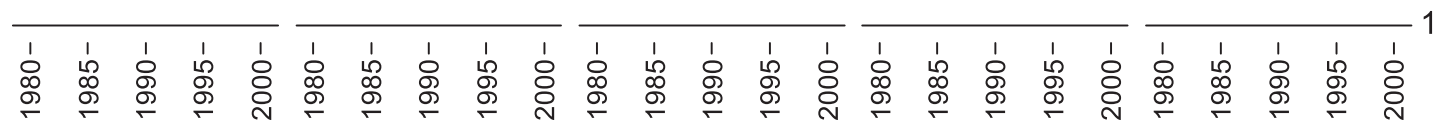

Source: Vital Statistics.

Figure 2. Trends of age-specific lung cancer mortality rates (male).

(per 100,000)

All prefectures

Miyagi

Niigata

Okayama

Gunma
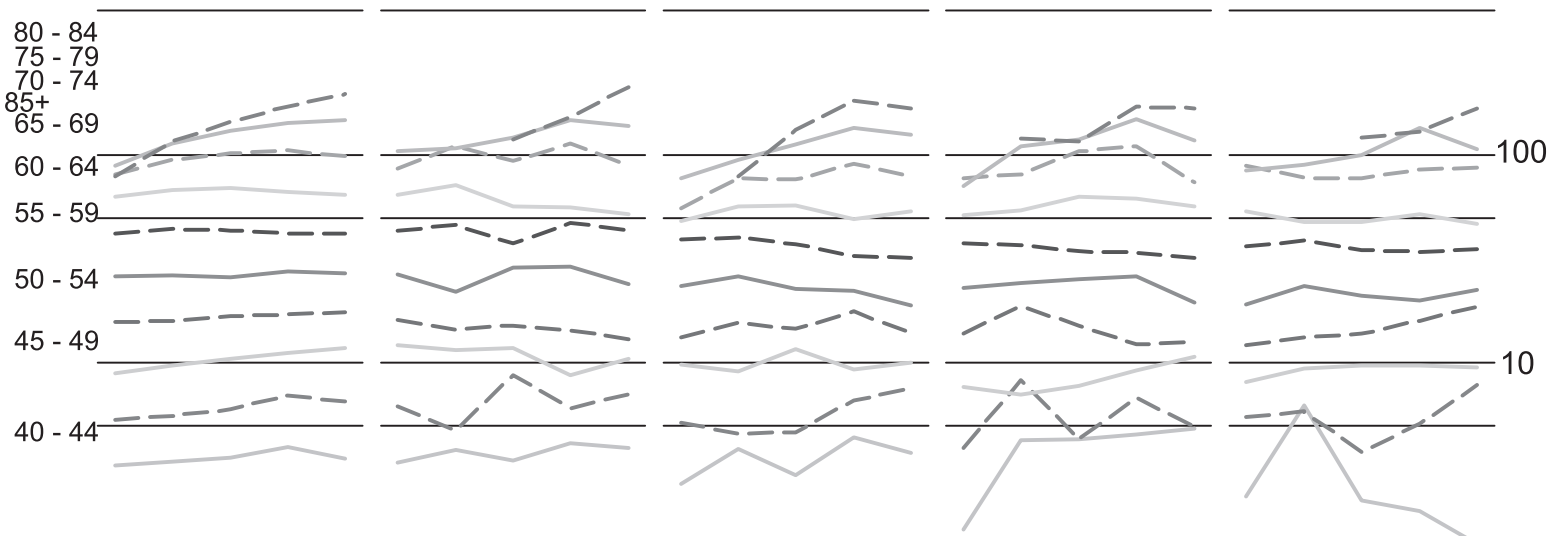

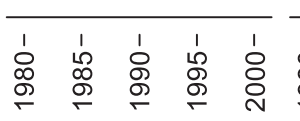
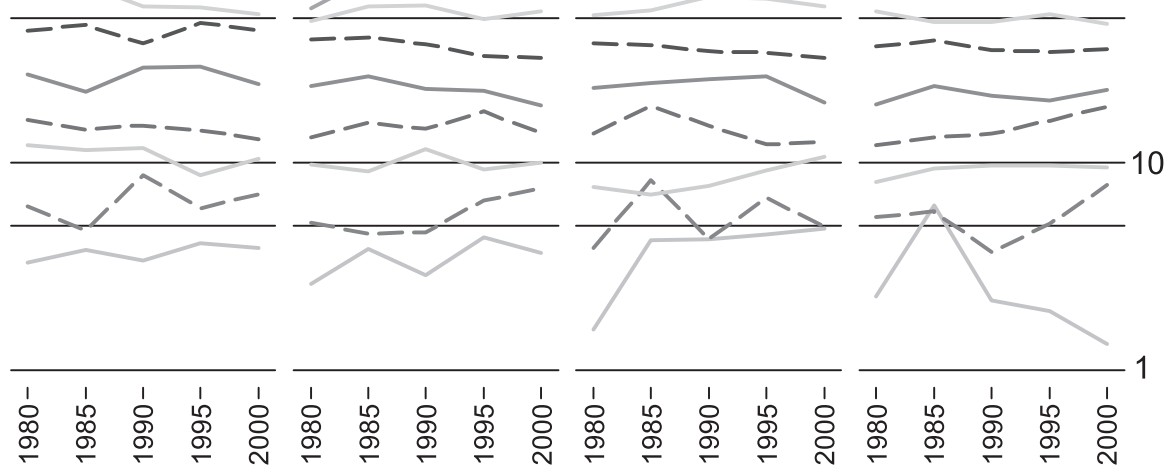

Source: Vital Statistics.

Figure 3. Trends of age-specific lung cancer mortality rates (female).

県レベルでかなりのばらつきが見られる.12 ただし，報 告に掲載されている受診率を計算する際の分母となる検 診対象者の計算方法は標準化されておらず，適切な比較
をすることができない，そこで，50～69 歳の年齢層に 限って，報告された受診者数を対応する年齢層の住民数 で割った值（カバー率）を計算し，都道府県別に年次推 
移を比較した（Figure 1). 全国の平均カバー率は，男性 で約 $10 \%$, 女性で約 $15 \%$ の水準でほぼ不変であるが, 宮 城, 新潟, 岡山県では, 全国平均を上回る水準を推移し ており，特に女性では 1998 年までは 40\%を上回るカ バー率を示していた。これらの県はいずれも過去に, 症 例対照研究による肺がん検診の有効性評価が実施された 県である. 群馬県においても症例対照研究が実施されて いるが, カバー率は上記 3 県とは異なり, 全国平均の近 い水準を推移していた.

肺がん年歯階級死亡率の年次推移を, 全国值および上 記 4 県について図示した (Figure 2，3)，男性では，全国 と上記 4 県との間で年次推移の違いは認められないが, 女性では, 40 歳代後半から 50 歳代にかけて, 全国に比べ た場合の上記 3 県の死亡率の減少程度がより大きいこと が示唆された．全国と上記 3 県をまとめた年歯令調整死亡 率 (50〜 74 歳に限定し, 昭和 60 年モデル人口を基準人口 として使用）について, Joinpoint 解析を行うと, 上記 3 県についてのみ, 1984 年以降の減少傾向が有意であると の結果であった．上記 3 県では，カバー率が高いことに 加えて, 精度の高い検診が行われていることが, その理 由と考えられる。

\section{REFERENCES}

1. Sobue T, Suzuki T, Naruke T. A case-control study for evaluating lung-cancer screening in Japan. Japanese Lung-Cancer-Screening Research Group. Int J Cancer. 1992;50:230-237.

2. Okamoto N, Suzuki T, Hasegawa H, et al. Evaluation of a clinic-based screening program for lung cancer with a case-control design in Kanagawa, Japan. Lung Cancer. 1999;25:77-85.
3. Sagawa M, Tsubono Y, Saito Y, et al. A case-control study for evaluating the efficacy of mass screening program for lung cancer in Miyagi Prefecture, Japan. Cancer. 2001;92:588-594.

4. Tsukada H, Kurita Y, Yokoyama A, et al. An evaluation of screening for lung cancer in Niigata Prefecture, Japan: a population-based case-control study. Br J Cancer. 2001; 85:1326-1331.

5. Nishii K, Ueoka H, Kiura K, et al. A case-control study of lung cancer screening in Okayama Prefecture, Japan. Lung Cancer. 2001;34:325-332.

6. Nakayama T, Baba T, Suzuki T, et al. An evaluation of chest X-ray screening for lung cancer in gunma prefecture, Japan: a population-based case-control study. Eur J Cancer. 2002;38:1380-1387.

7. 久道 茂. 平成 12 年度厚生労働省老人保健事業推進費等 補助金. がん検診の適正化に関する調査研究事業「新た ながん検診手法の有効性の評価」報告書. 東京 : 日本公衆 衛生協会；2001.

8. U.S. Preventive Services Task Force. Guide to Clinical Preventive Services. 2nd ed. 1996. (http://www.ahrq.gov/ clinic/cpsix.htm)

9. U.S. Preventive Services Task Force. Screening for Lung Cancer. 2004. ( http:// www.ahrq.gov/ clinic/ uspstf / uspslung.htm)

10. Berry DA, Cronin KA, Plevritis SK, et al. Effect of screening and adjuvant therapy on mortality from breast cancer. $N$ Engl J Med. 2005;353:1784-1792.

11. Ajiki W, Kinoshita N, Tsukuma $\mathrm{H}$, et al. Cancer Incidence and incidence rates in Japan in 1996: estimates based on data from 10 population-based cancer registries. Jpn J Clin Oncol. 2001;31:410-414.

12. 地域保健 · 老人保健事業報告. 平成 $4 \sim 14$ 年度厚生労働 省大臣官房統計情報部, 編集. 東京 : 厚生統計協会 ; 1994-2004. 